Acta Cryst. (2002). A58 (Supplement), C196

\section{SELECTING THE MOST LIKELY PREDICTED POLYMORPHS USING THE CAMBRIDGE STRUCTURAL DATABASE}

\section{S. Motherwell}

Cambriidge Crystallographic Data Centre 12 Union Road CAMBRIDGE CB2 $1 \mathrm{EZ} \mathrm{UK}$

Recent workshops $(1,2)$ held at the CCDC on blind test crystal structure prediction of small organic molecules have shown some moderate success. However, the procedure can not be regarded as routine and reliable, and flexible molecules present great difficulties. Most methods produce a list of possible polymorphs within a very small lattice energy window of $<1$ $\mathrm{kcal} / \mathrm{mole}$ of the global minimum, and decisions as to the most likely polymorph are often taken on tiny energy differences. Since the current methods do not take account of the kinetics of crystallization, solvents or temperature, the choice on energy alone may seem rather optimistic, but nevertheless the best criterion we have at present. This has led to several correct predictions at each workshop.

Attempts have been made to utilize the CSD (over 250,000 structures) to find patterns to provide empirical fitting indices, hoping that recurrent patterns for similar molecules may indicate the most likely polymorph at room temperature and pressure. Examples will be given of using H-bond motifs, contacts of chemical functional groups, distribution of void-space, hydrophobic/hydrophilic regions in the crystal, and distribution of packing energy within the molecular coordination sphere. Although certain polymorphs may be eliminated form the short-list, there is much work to be done to produce reliable ranking of polymorph occurrence.

References

(1) Lommerse et al. (1999). Acta Cryst. B56, 697-714.

(2) Motherwell et al. (2002). Acta Cryst. B, submitted.

\section{Keywords: STRUCTURE PREDICTION DATABASES PATTERNS}

\section{Acta Cryst. (2002). A58 (Supplement), C196 \\ TOWARDS METAL-RADICAL SUPRAMOLECULAR ZEOTYPE MAGNETS. NEW MAGNETIC NANOPOROUS MATERIALS J. Veciana ${ }^{1}$ D. Maspoch ${ }^{1}$ D. Ruiz-Molina ${ }^{1}$ C. Rovira ${ }^{1}$ K. Wurst ${ }^{2}$ \\ ${ }^{1}$ Institut De Ciencia De Materiales De Barcelona (CSIC) Laboratori De Materials Organics Caampus Universitari De Bellaterra CERDANYOLA E- 08193 SPAIN ${ }^{2}$ Institut fur Allgemeine Anorganische und Teoretische Chemie, Universitat Innsbruck}

The assembly of nanoporous materials from soluble molecular building blocks is an emerging area yielding new generations of supramolecular architectures with zeolite-like structures. Intense research activities directed toward the development of this field have included the assembly of inorganic metal clusters, coordination complexes and organic molecules of great diversity into extended motifs that are held together either by strong metal-ligand bonding or by weaker bonding forces such as hydrogen bond and p-p interactions.

In this communication we present new nanoporous magnetic materials based on polychlorotriphenylmethyl radicals and paramagnetic metal ions. The mono- and tricarboxylic radicals have been synthesized and successfully used as ligands to obtain transition metal complexes with different magnetically active metal ions such as $\mathrm{Cu}(\mathrm{II}), \mathrm{Ni}$ (II) or $\mathrm{Co}(\mathrm{II})$. The resulting compounds range from clusters to 3-D supramolecular structures with nanoporous of a few nanometers. The magnetic properties of such new type of materials will be described and correlated with their structures.

\section{Keywords: MAGNETISM, NONOPOROUS, FREE RADICALS}

Acta Cryst. (2002). A58 (Supplement), C196

\section{THE PREDICTION OF CLOSE PACKED AND POROUS INORGANIC CRYSTAL STRUCTURES}

S.M. Woodley ${ }^{1}$ C.R.A. Catlow ${ }^{1}$ P.D. Battle ${ }^{2}$ J.D. Gale ${ }^{3}$

${ }^{1}$ Royal Institution of Great Britain D.F.R.L. 21 Albemarle Street LONDON

W1S 4BS UK ${ }^{2}$ Inorganic Chemistry Laboratory, University of Oxford

${ }^{3}$ Department of Chemistry, Imperial College

There are an immense number of possible atomic arrangements that can be generated from the knowledge of the unit cell lattice parameters and constituents. Therefore finding the crystal structure that produces the 'observed' powder diffraction pattern can still be intractable, in some cases, without further information. Hence, techniques for structure prediction have a role to play. Our method (Phys. Chem. Chem. Phys. 19911 2535-2542) assumes that the required structure has a lattice energy at either the global minimum or a local minimum of a similar depth. By implementing a genetic algorithm(GA) to generate plausible structures followed by a local optimizer, in order to increase the accuracy of the atomic coordinates, we have efficiently found the structures of a wide range of known close packed oxides, including perovskites, pyrochlores and spinels. Our method, which is capable of reproducing different phases of a compound, is based upon that developed by Bush et al (1995) who successfully predicted the previously unknown structure of $\mathrm{Li}_{3} \mathrm{RuO}_{4}$. The method has been implemented within the General Utility Lattice Program (GULP), thus facilitating the calculation of the physical properties (for example, elastic constants) of the phase. Now this method has been extended to enable the prediction of porous materials. To accelerate and guide the GA when trying to generate such materials, several techniques have been investigated, including a simple additive penalty to the cost function when an ion is within a defined 'exclusion zone'(EZ) and the use of a nonlinear grid that has no points within EZ. Further refinements currently being investigated include the use of polyatomic units and symmetry information.

\section{Keywords: STRUCTURE PREDICTION GENETIC ALGORITHM LATTICE ENERGY}

\section{Acta Cryst. (2002). A58 (Supplement), C196}

\section{A NEW MANGANESE CARBOXYLATE CLUSTER:} $\left[\mathrm{Mn}_{16} \mathrm{O}_{16}(\mathrm{OMe})_{6}(\mathrm{OAc})_{16}(\mathrm{MeOH})_{3}\left(\mathrm{H}_{2} \mathrm{O}\right)_{3}\right] .6 \mathrm{H}_{2} \mathrm{O}(\mathrm{Mn16}$-acetate $)$ S.R. Batten ${ }^{2}$ D.J. Price ${ }^{1}$ B. Moubaraki ${ }^{3}$ K.S. Murray ${ }^{4}$

${ }^{1}$ School of Chemistry, Monash University, Clayton, Victoria 3800 AUSTRALIA

Since it was discovered in 1993,[1] that $\left[\mathrm{Mn}_{12} \mathrm{O}_{12}(\mathrm{OAc})_{16}\left(\mathrm{H}_{2} \mathrm{O}\right)_{4}\right] .2 \mathrm{HOAc} .4 \mathrm{H}_{2} \mathrm{O}$ ('Mn12-acetate') behaves as a discrete nanosized magnetic particle (nanomagnet or single molecule magnet, SMM), research in the field of polynuclear manganese carboxylate clusters has become widespread.[2] Synthetic and physicochemical studies made by Christou and Hendrickson et al.,[2] Gatteschi and Sessoli et al.,[3] and Powell et al.[4] on high nuclearity manganese and iron oxo/carboxylato cluster complexes have led to significant advances being made in the understanding of SMMs. In addition, some iron and vanadium clusters have been shown to display the characteristics peculiar to the SMM family.[5] Here we present a new member of this family,[6] the title compound. Its discovery was fortuitous. The structure of the cluster can be divided into two sub-units, a central $\left[\mathrm{Mn}(\mathrm{IV})_{6} \mathrm{O}_{6}(\mathrm{OMe})_{4}\right]^{8+}$ unit connected to an outer $\mathrm{Mn}(\mathrm{III})_{10}$ perimeter by ten $\mu 3-$ $\mathrm{O}^{2-}$ ions and two $\mu 2-\mathrm{OAc}$ groups. Peripheral ligation consists of the remaining fourteen $\mu 2-\mathrm{OA} \dot{c}$, two $\mu 2$-OMé groups and three axial water and methanol molecules. Preliminary magnetic measurements, particularly frequency dependence of the $\chi^{\prime}$ signal in the AC susceptibility, indicate this new cluster is an SMM.

References

[1] R. Sessoli, H.-L. Tsai, A.R. Schake, S. Wang, J.B. Vincent, K. Folting, D. Gatteschi, G. Christou, and D.N. Hendrickson, J. Am. Chem. Soc., 1993, 115, 1804.

[2] G. Aromi, S. Aubin, M. J., M. Bolcar, A., G. Christou, H. J. Eppley, K. Folting, D. N. Hendrickson, J. C. Huffman, R. Squire, C., H.-L. Tsai, S. Wang, and M. W. Wemple, Polyhedron, 1998, 17, 3005.

[3] A. Caneschi, D. Gatteschi, C. Sangregorio, R. Sessoli, L. Sorace, A. Cornia, M. A. Novak, C. Paulsen, and W. Wernsdorfer, J. Magn. Magn. Mater., 1999, $200,182$.

[4] A. K. Powell, Struct. Bonding, 1997, 88, 1.

[5] G. Christou, D. Gatteschi, D. N. Hendrickson, and R. Sessoli, Materials Research Society Bulletin, 2000, 25, 66.

[6] D. J. Price, S. R. Batten, B. Moubaraki, K. S. Murray, Chem. Commun., 2002, in press. 